\title{
Leitura e compreensão de leitura em língua estrangeira
}

\section{Reading and reading comprehension in a foreign language}

https://doi.org/10.34112/2317-0972a2021V39n81p31-46

MARINA GRILLI ${ }^{1}$

RESUMO: Este trabalho apresenta modelos teóricos da compreensão de leitura e estabelece correlações entre eles e os desafios encontrados, ao elaborar testes de verificação da leitura em língua estrangeira (LE). O ponto de partida foi a ideia de que compreensão de leitura e compreensão de texto são diferentes. Após descrever os conceitos de texto e leitor, comparam-se aqui os processos da compreensão e as estratégias de leitura em LM e em LE, a fim de refletir sobre a leitura em LE e responder a duas questões: por que a compreensão de leitura é mais complexa que a compreensão de um texto, e por que é importante considerar isso ao testar a leitura em LE?

PALAVRAS-CHAVE: Leitura; compreensão de leitura; leitura em língua estrangeira.

ABSTRACT: This paper presents theoretical models of reading comprehension and establishes correlations between them and the challenges encountered in the development of reading tests in FL. The starting point was the idea that reading comprehension is different from text comprehension (WÜRFFEL, 2013). After describing the concepts of text and reader, we compare the comprehension processes and the reading strategies in the $M L$ and the FL, reflecting on reading in FL in order to answer two questions: why reading

1. Universidade de São Paulo, SP, Brasil. 
comprehension is more complex than text comprehension and why it is important to consider this information when testing the reading in FL.

KEYWORDS: Reading; reading comprehension; reading in a foreign language.

\section{INTRODUÇÃO}

Em primeiro lugar, o que é a leitura?

Jouve (2002, p. 18) afirma que a leitura é "uma atividade de antecipação, de estruturação e de interpretação", constituída de cinco dimensões: neurofisiológica, cognitiva, afetiva, argumentativa e simbólica. Para Ehlers (2007, p. 287), é um procedimento que parte de processos primários de percepção, passa pelo reconhecimento de palavras e chega até os mais complexos processos de significação. E, nas palavras de Koch e Elias (2006, p. 57), a leitura ainda "requer a mobilização de um vasto conjunto de saberes".

Em segundo lugar, para que serve a leitura?

De acordo com Vilson Leffa (1999, p. 25), a atividade de leitura pode ter diversos objetivos: "objetivos puramente práticos ou ocupacionais", recreativos, afetivos ou ritualísticos. Já o Quadro Europeu Comum de Referência para as Línguas, importante documento publicado em 2001, destinado a descrever os níveis de proficiência que permitem medir o progresso do falante de uma língua, menciona também quatro possíveis objetivos, que diferem ligeiramente daqueles elencados por Leffa. São eles: ler para orientação geral, para obter informações, para seguir instruções e por prazer (Conselho da Europa, 2001, p. 106).

No presente artigo, trataremos dos principais conceitos relacionados à competência de leitura: o texto, o leitor, os processos e os níveis em que se processa a leitura, e as estratégias que podem ser empregadas conforme o objetivo da atividade de leitura. Assim, demonstraremos por que a compreensão de leitura envolve mais do que o ato de compreender um único texto. Também relacionaremos esses conceitos às especificidades da leitura em língua estrangeira (doravante LE) e apresentaremos, com base nos conceitos teóricos, por que é importante tê-los em mente ao pensar instrumentos para testar a leitura em LE. 
Segundo Koch (2007, p. 11), o texto é o produto de "uma atividade verbal, numa situação dada, com vistas a certos resultados". Para a perspectiva interacional ou dialógica da língua, que considera a interação entre autor, texto e leitor, o sentido de um texto não existe por si só, mas é construído na interação entre essas três instâncias (KOCH; ELIAS, 2006, p. 11).

Um texto é considerado aberto quando admite múltiplas possibilidades de interpretação, de acordo com o leitor que participa da construção de seu significado; é considerado fechado quando direcionado a um tipo mais específico de público, por exemplo, pesquisadores da didática de LEs. A esse respeito, Umberto Eco (1983, p. 56-57) chega à conclusão de que, quanto mais fechado, isto é, quanto mais especificamente orientado para um público, mais aberto parecerá o mesmo texto para outros públicos, que terão a tarefa de inferir uma série de significados.

O destinatário é um elemento sempre presente nas mais diversas concepções de texto, por ser este um instrumento de comunicação. Eco (1983, p. 50-51) afirma que o texto sempre pressupõe um leitor que domine o código no qual o texto está escrito, a fim de compreender a mensagem que tal texto pretende transmitir. Em outras palavras, sem um leitor pressuposto, um texto seria ininteligível (ECO, 1983, p. 59). De acordo com Leffa (1999, p. 33), a pressuposição do leitor estabelece parâmetros para a atribuição de sentido em um texto.

Para essa operação de inferência, o contexto exerce papel crucial na compreensão de leitura. Algumas particularidades do contexto serão exploradas mais adiante.

Porém, Eco lembra também que a competência do destinatário do texto não é necessariamente a mesma do autor (ECO, 1983, p. 53); desse modo, nem todo leitor é o leitor idealmente competente.

Essa constatação leva ao seguinte questionamento: o que é um leitor ideal? De acordo com os Parâmetros Curriculares Nacionais para o ensino de Língua Portuguesa (BRASIL, 1997, p. 41),

um leitor competente é alguém que, por iniciativa própria, é capaz de selecionar, dentre os trechos que circulam socialmente, aqueles que podem atender a uma necessidade sua. Que consegue utilizar estratégias de leitura adequadas para abordá-los de forma a atender a essa necessidade. 
O livro eletrônico sobre compreensão de leitura, elaborado pelo grupo estadunidense Pacific Resources for Education and Learning (PREL, 2005, p. 8-9), segue a mesma linha de definição de um bom leitor: antes de ler, ele ativa sua rede de conhecimentos prévios - ou seja, quanto maior o alcance dessa rede, maiores as chances de o leitor compreender o que lê. Bons leitores também fazem uso de seus conhecimentos prévios sobre o assunto do texto para estabelecer expectativas e, durante a leitura, refletem sobre sua compreensão do texto e sobre como melhorá-la. Depois de ler, podem refletir sobre a utilidade das informações obtidas e decidir se gostaram do texto.

Segundo Lutjeharms (2010, p. 976), desde a popularização da abordagem comunicativa no ensino de LE, a leitura vem deixando de ser percebida como competência 'passiva', pois o leitor interage ativamente com o texto através do uso de seus conhecimentos prévios e de sua capacidade de interpretação.Já segundo Ehlers (2007, p. 288), o leitor modifica seu comportamento de acordo com diversas variáveis, adaptando-o aos objetivos da atividade de leitura, ao tipo de informação que pretende abstrair do texto e ao nível de profundidade dessa informação, bem como a fatores externos que concorrem para a situação de leitura. Essa mudança de comportamento significa que o leitor seleciona a estratégia de leitura mais adequada às variáveis envolvidas.

A perspectiva do leitor, porém, não é a única forma de compreender o fenômeno da leitura como mais complexo do que uma mera extração do conteúdo inerente ao texto: Leffa (1999, p. 14) lembra que um leitor pode atribuir a um texto determinados significados, dos quais outro leitor poderia vir a discordar.

Ademais, Meireles (2006, p. 299) afirma que o conteúdo e a coerência de um texto não surgem da mera decodificação dos signos linguísticos. Segundo o PREL (2005, p. 5), definir a compreensão de leitura como "construir significado a partir do texto" não faz jus à complexidade do fenômeno da compreensão e dos muitos fatores que ela abarca - mais do que isso, a compreensão de leitura seria "o processo de extrair e construir significado simultaneamente, através da interação e do envolvimento com a língua escrita". Portanto, "um processo multidimensional que envolve fatores relativos ao leitor, ao texto e à atividade” (PREL, 2005, p. 6), conforme já comentado na seção anterior.

Meireles (2006, p. 300) também lembra que a compreensão de leitura depende não só do conhecimento linguístico, mas também de elementos como o conhecimento prévio do conteúdo, as expectativas do leitor e o contexto - afinal, não existe conexão direta entre o texto e a representação mental que o leitor faz dele. 
Desse modo, alguns dos modelos propostos para descrever a compreensão de leitura consideram as estruturas do texto e o vocabulário como os principais fatores que a influenciam; outros se baseiam no modo através do qual o leitor absorve as informações contidas no texto; e outras linhas teóricas, por sua vez, consideram como chave para a compreensão as estratégias de interação entre os conhecimentos prévios do leitor, o conteúdo do texto e o contexto da situação de leitura. A diferenciação de Leffa (1999) entre esses três tipos de abordagens pode ser assim resumida:

\begin{tabular}{|c|c|c|}
\hline \multicolumn{3}{|c|}{ Perspectivas da compreensão de leitura } \\
\hline Abordagens & Ênfase & Construção de sentido \\
\hline ascendentes & texto & extração \\
\hline descendentes & leitor & atribuição de significados \\
\hline conciliadoras & texto + leitor & interação \\
\hline
\end{tabular}

Quadro 1. Abordagens da leitura e suas principais características, com base em Leffa (1999, p.13)

Mas qual é o papel do autor em todo esse processo? Segundo Eco (1983, p. 5456), na falta da reação do interlocutor, recurso presente em situações de comunicação oral, o autor do texto escrito assume o papel de um estrategista que prevê o movimento do "adversário": ele lança mão de técnicas para recuperar aquele leitor que poderia se perder e abandonar o texto diante de uma referência desconhecida.

Assim, Eco vai além da definição do leitor competente e prevê um "leitor modelo", capaz de cooperar com o texto, baseando-se nas mesmas referências pensadas pelo autor. Pressupor esse leitor modelo não é sinônimo de simplesmente esperar que ele exista, mas de "mover o texto de modo a construí-lo" (ECO, 1983, p. 54-56). Este é o papel que o autor assume na relação entre texto e leitor.

Ao postular o conceito de leitor modelo, Umberto Eco refere-se principalmente ao universo da literatura, mas não é difícil perceber a relevância de suas afirmações também no âmbito do texto acadêmico-científico: por vezes, o leitor que não conhece as referências teóricas citadas não consegue acompanhar a linha de pensamento do artigo. Segundo Jouve (2002, p. 74), "a antecipação e a simplificação são os dois reflexos básicos da leitura”: entender o enunciado é reconhecer nele uma intenção, levantando hipóteses e antecipando o tópico que será tratado. Para Leffa (1999, p. 29), na medida em que a compreensão de leitura passa a simbolizar 
pertencimento a um seleto grupo de leitores modelo, $\mathrm{o}$ ato de ler deixa de ser individual para tornar-se comportamento social.

\section{Processos que permeiam a leitura}

Leffa (1999, p. 23) lista três tipos de conhecimento que contribuem para o processamento textual: o conhecimento linguístico, que envolve a consciência fonológica, a decodificação do sistema ortográfico, o conhecimento sintático e semântico; o conhecimento textual, relativo à estrutura dos gêneros textuais; e o conhecimento enciclopédico, que consiste no acionamento da memória episódica. Já Meireles (2006, p. 301) distribui essas categorias entre conhecimento linguístico e conhecimento enciclopédico, de modo que o conhecimento enciclopédico abrange as estratégias de comportamento adequadas a diversas situações. Para a autora, nesses dois tipos de conhecimentos se baseia a habilidade de entender além daquilo que está explícito no texto (MEIRELES, 2006, p. 307).

Koch (2007, p. 32) desenvolve essas definições, diferenciando três sistemas complexos de conhecimento: o linguístico, o sociointeracional e o enciclopédico. O seguinte esquema representa as subcategorias de cada um deles, e o Quadro 2 traz suas definições:

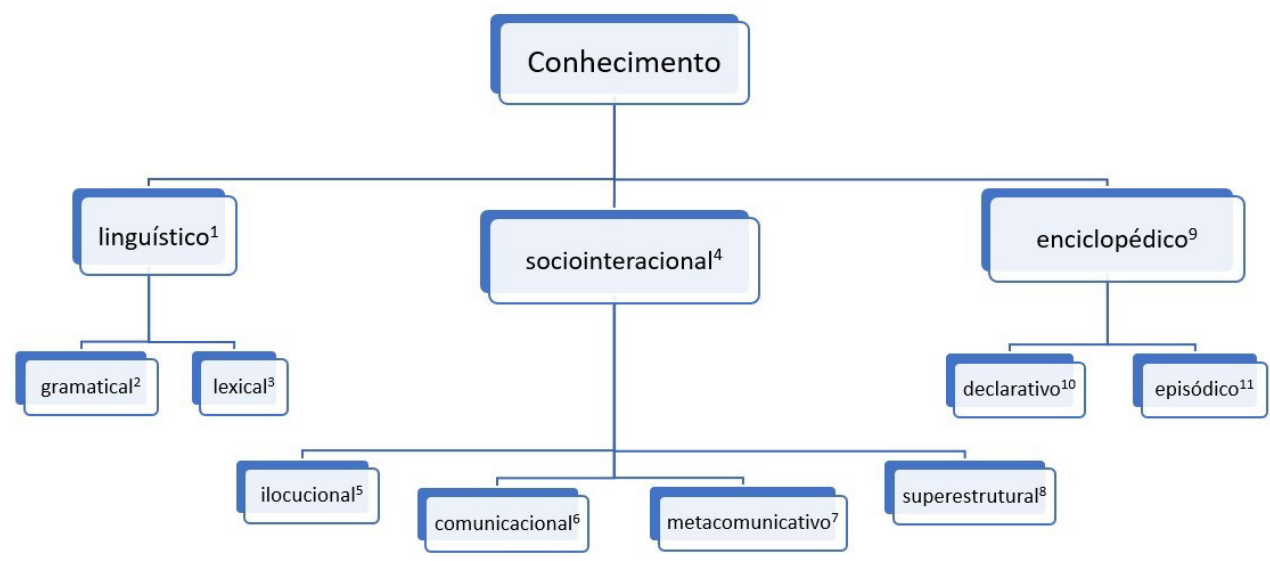

Figura I. Esquematização dos sistemas de conhecimento, baseada em Koch (2007, p. 32-33) 
1. O conhecimento linguístico compreende o conhecimento gramatical e o lexical, sendo o responsável pela articulação som-sentido.

2. O conhecimento gramatical relaciona-se à organização do material linguístico na superfície textual e ao uso dos meios coesivos para remissão ou sequenciação textual.

3. O conhecimento lexical está relacionado à seleção lexical adequada.

4. O conhecimento sociointeracional é o conhecimento sobre as ações verbais, isto é, sobre as formas de inter-ação através da linguagem. Engloba os conhecimentos do tipo ilocucional, comunicacional, metacomunicativo e superestrutural.

5. O conhecimento ilocucional é o conhecimento a respeito dos tipos de atos de fala, que leva a reconhecer os objetivos de um falante em dada situação de interação.

6. O conhecimento comunicacional está relacionado à quantidade de informação necessária e à seleção da variante linguística empregada.

7. O conhecimento metacomunicativo tem a ver com os sinais ou recursos que permitem assegurar a compreensão do texto e evitar conflitos.

8. O conhecimento superestrutural permite reconhecer textos como pertencentes a tal gênero, e a conexão entre objetivos e estruturas textuais.

9. O conhecimento enciclopédico ou conhecimento de mundo é aquele que se encontra armazenado na memória de cada indivíduo, e pode ser de tipo declarativo ou episódico.

10. O conhecimento declarativo representa as proposições a respeito dos fatos.

11. O conhecimento episódico vem dos 'modelos cognitivos' socioculturalmente determinados e adquiridos através da experiência.

Quadro 2. Definição dos sistemas de conhecimento, baseada em Koch (2007, p. 32-33)

Segundo Koch (2007, p. 34), a cada um desses três grandes sistemas corresponde um conhecimento procedural, isto é, um sistema que integra os conhecimentos aqui descritos a estratégias de interação, a fim de colocar os conhecimentos em prática. Esse sistema, denominado conhecimento procedural, vem à tona no momento em que o sujeito entra em contato com o texto. Afinal, "o sentido de um texto não existe a priori, mas é construído na interação sujeitos-texto" (KOCH; ELIAS, 2006, p. 57). Desse modo, a produção de sentido exige que se leve em conta o contexto. 
O contexto, por sua vez, é definido por Koch e Elias (2006, p. 64) como "constitutivo da própria ocorrência linguística", como "um conjunto de suposições, baseadas nos saberes dos interlocutores, mobilizadas para a interpretação de um texto". Ele funciona da seguinte forma:

em uma situação de comunicação, os interlocutores situam o seu dizer em um determinado contexto - que é constituinte e constitutivo do próprio dizer - e vão alterando, ajustando ou conservando esse contexto no curso da interação, visando à compreensão. [...] O contexto engloba não só o co-texto, como também a situação de interação imediata, a situação mediata (entorno sociopolítico-cultural) e o contexto cognitivo dos interlocutores. (KOCH; ELIAS, 2006, p. 63)

Esse contexto cognitivo "reúne todos os tipos de conhecimentos arquivados na memória dos atores sociais, que necessitam ser mobilizados por ocasião do intercâmbio verbal" (KOCH; ELIAS, 2006, p. 63 ).

Subjacente a ele, há ainda o contexto sociocognitivo, no qual ocorrem interações entre sujeitos: "para que duas ou mais pessoas possam compreender-se mutuamente, é preciso que seus contextos sociocognitivos sejam, pelo menos, parcialmente semelhantes" (KOCH; ELIAS, 2006, p. 61). Em outras palavras, o conceito de contexto sociocognitivo guarda semelhanças com o que se espera do leitor modelo de Eco, na medida em que dois atores do processo, autor e leitor, devem compartilhar referências.

Também a definição de contexto fornecida pelas autoras se assemelha muito à de conhecimento sociointeracional de Koch (2007, p.32), que trata do conhecimento sobre os tipos de discurso, sobre quais informações devem ser compartilhadas de forma explícita e quais fazem parte de um contrato implícito. Melhor dizendo, o conhecimento sociointeracional é o conhecimento acerca do contexto em que se inserem o leitor e o texto.

Würffel (2013, p. 132) cita o conhecido modelo situacional para a compreensão textual, pensado por Van Dijk e Kintsch (1983), de acordo com o qual o uso das informações do texto e dos conhecimentos do leitor é percebido como processo estratégico, flexível, dirigido pela intenção do leitor e inserido num contexto sociocultural. Fatores internos ao leitor - conhecimento, intenção, emoções e motivação -, bem como fatores externos: o texto, suas exigências e as tarefas propostas, influenciam a mobilização de estratégias de leitura. 
Com base em todas as informações elencadas aqui, diferenciam-se os seguintes fatores que concorrem para o processamento textual: por parte do leitor, tem-se o conhecimento sociointeracional ou relativo ao contexto, o conhecimento linguístico e o conhecimento de mundo. Do outro lado, temos o texto e o gênero a que pertence, a língua em que está escrito e as tarefas que o leitor deve realizar a partir dele.

Agora, pensemos mais especificamente na atividade de leitura, tanto em sua concepção mais ampla quanto no âmbito da aprendizagem de LE.

\section{Níveis da Compreensão de leitura}

O Quadro Comum Europeu de Referência para Línguas estabelece os seguintes níveis de compreensão de leitura - ou "compreensão escrita" -, de acordo com o conhecimento que o leitor tem da língua em que o texto se encontra.

\begin{tabular}{|c|l|}
\hline \multicolumn{2}{|c|}{ A compreensão de leitura segundo o Quadro Comum Europeu } \\
\hline Nível & \multicolumn{1}{c|}{ Descrição } \\
\hline A1 & $\begin{array}{l}\text { É capaz de entender textos muito curtos e muito simples, a partir de palavras e ex- } \\
\text { pressões básicas. }\end{array}$ \\
\hline A2 $_{2}$ & $\begin{array}{l}\text { É capaz de entender textos simples e curtos acerca de assuntos que lhe são fami- } \\
\text { liares, compostos numa linguagem frequente e que contenham vocabulário muito } \\
\text { usual, incluindo uma certa proporção de vocábulos internacionais. }\end{array}$ \\
\hline $\mathrm{B}_{1}$ & $\begin{array}{l}\text { É capaz de ler textos objetivos simples acerca de assuntos relacionados com a sua área } \\
\text { de interesse, com um grau satisfatório de compreensão. }\end{array}$ \\
\hline $\mathrm{B}_{2}$ & $\begin{array}{l}\text { É capaz de ler com um elevado grau de independência, adaptando o estilo e a velo- } \\
\text { cidade de leitura e utilizando de forma seletiva fontes de referência adequadas. Pode } \\
\text { sentir alguma dificuldade com expressões idiomáticas pouco frequentes. }\end{array}$ \\
\hline $\mathrm{C}_{1}$ & $\begin{array}{l}\text { É capaz de entender em pormenor textos longos e complexos, relacionados ou não } \\
\text { com a sua área de especialidade, desde que possa voltar a ler as seções difíceis. }\end{array}$ \\
\hline $\mathrm{C}_{2}$ & $\begin{array}{l}\text { É capaz de ler e de interpretar criticamente praticamente todas as formas delíngua escrita e } \\
\text { de entender um vasto leque de textos longos e complexos, apreciando distinções de estilo } \\
\text { sutis, significados implícitos e explícitos. }\end{array}$ \\
\hline
\end{tabular}

Quadro 3. Níveis da compreensão de leitura, com base no Quadro Comum Europeu de Referência para Línguas (levemente adaptado de CONSELHO DA EUROPA, 2001, p. 107) 
Naturalmente, como demonstra o Quadro 3, a compreensão de leitura tem início na compreensão de palavras e expressões isoladas, evoluindo para textos de temática familiar, até atingir gêneros textuais e temas mais complexos.

Diversos pesquisadores já subdividiram o processo de compreensão de leitura em modelos, tipos e níveis. Faremos a seguir uma breve revisão de alguns deles, baseados nas abordagens sociointeracional e cognitivista.

O PREL (2005, p. 7) distingue dois níveis no processo de leitura, ambos fundamentais para uma compreensão eficaz do texto: as habilidades básicas, nível em que se reconhecem e decodificam palavras e se obtém a fluência; e os processos de leitura de ordem elevada, que abrangem os procedimentos que entram em ação quando o leitor estabelece conexões entre as palavras e entre seus conhecimentos prévios e as informações presentes no texto.

Falando especificamente da leitura em LE, Würffel (2006, p. 67) defende, desde o início da aprendizagem de uma LE, o estímulo concomitante das habilidades básicas e dos processos de compreensão mais elevados. Lutjeharms (2010) cita quatro níveis que compõem o processo de leitura em LE: o nível grafofônico, o reconhecimento de palavras, o processamento sintático e o processamento semântico.

Würffel $(2006,2013)$ também distingue níveis de processamento: da palavra, da frase e do texto. E Blühdorn e Albert (2012) estabelecem as seguintes estruturas gramaticais e textuais que concorrem para a compreensão textual aprofundada, desde que o leitor esteja minimamente familiarizado com as regras da língua em questão: a superfície visível do texto, as convenções ortográficas, as estruturas sintáticas e os períodos compostos.

Portanto, parece haver um consenso de que o processo da leitura se constrói em camadas. O processamento do leitor experiente, segundo Lutjeharms (2010, p. 977), segue a ordem de complexidade descrita por esses autores, indo do nível mais baixo ao mais alto - sentido conhecido como bottom-up.

Quanto à compreensão do conteúdo lido, Lutjeharms (2010) cita dois tipos de processamento: o automático e o consciente. $\mathrm{O}$ processamento automático é rápido e envolve diversos processos em paralelo - certamente, a decodificação de palavras e de estruturas sintáticas, o processamento sintático e semântico, o estabelecimento de conexões entre todas essas informações e seus conhecimentos prévios. Já o processamento consciente se faz necessário para processar informações inesperadas ou ilógicas para o leitor, quando suas limitações dificultam a tarefa de apreender o conteúdo. 
A esse respeito, a teoria psicolinguística da compensação afirma o seguinte: quando há um déficit em uma das fontes de conhecimento que o leitor ativa durante a leitura, ele consegue compensar esse déficit usando conhecimentos de outro domínio. Por exemplo, na falta de vocabulário, o conhecimento prévio sobre o tema do texto pode auxiliar o leitor a inferir o significado do termo que não conhece (LEFFA, 1999, p. 29).

Meireles (2006, p. 301), por sua vez, diferencia outros dois tipos de processamento: aquele que vai "de baixo para cima", guiado pelas palavras e frases do texto em direção à compreensão de seu sentido integral, também denominado bottom-up, e aquele que vai "de cima para baixo", partindo do conhecimento geral do leitor sobre o tema do texto, também chamado top-down.

Ehlers (2007, p. 287-288) resume o complexo conceito do processamento de leitura da seguinte forma: a leitura veloz, que é um pressuposto para a compreensão de leitura, se deve ao fato de o reconhecimento das palavras acontecer de forma independente do contexto, isto é, sem influência do que foi lido previamente nem de conhecimentos anteriores ao momento da leitura. Leffa (1999, p. 20) também observa que "a grande maioria das palavras são reconhecidas antes que as informações contextuais possam influenciar o acesso lexical". Por sua vez, os processos que ultrapassam o nível da palavra contam com a participação de conhecimentos de mundo, expectativas e crenças.

Daí é possível deduzir que a dificuldade dos leitores menos proficientes para processar as palavras constitui um obstáculo para a compreensão nos níveis mais altos. Ehlers (2007, p. 288) afirma que o leitor está sempre realizando diversas tarefas em paralelo, e por isso as habilidades básicas devem estar automatizadas, para que ele volte sua atenção para os processos superiores, que exigem monitoramento.

De acordo com Lutjeharms (2010, p. 979-980) e Meireles (2006, p. 308), o reconhecimento de palavras e a análise sintática exigem atenção quando há falhas de processamento nos níveis mais baixos, tornando consciente o processo de compreensão de leitura. Essa falha na decodificação ou falta de conhecimento sobre o conteúdo acaba por deixar em segundo lugar o nível mais alto do processamento do texto, relativo à semântica, levando a possíveis equívocos no entendimento da mensagem do texto. Meireles (2006, p. 308) afirma que as estruturas abstratas que já estão disponíveis para o leitor, devido a seus conhecimentos prévios, possibilitam que ele armazene uma quantidade menor de informações durante a leitura do texto, aumentando assim a velocidade de leitura e processamento.

Como minimizar, então, os bloqueios na compreensão de leitura do aprendiz de uma nova língua? A próxima seção traz uma reflexão sobre estratégias de leitura. 


\section{Estratégias de leitura}

Em primeiro lugar, é válido reforçar que estratégias de leitura não devem ser confundidas com estratégias de processamento textual, sobre as quais já falamos anteriormente.

O uso de estratégias de leitura tem como finalidade facilitar a compreensão do texto. Segundo Leffa (1999), cada um daqueles objetivos da atividade de leitura mencionados na introdução pressupõe uma estratégia diferente de abordagem do texto. Nas palavras de Würffel (2013, p. 134), estratégias de leitura são "operações cognitivas opcionais que o aprendiz emprega de forma consciente ou inconscientemente intencional, para influenciar sua aquisição de conhecimento, para lidar com tarefas ou para atingir seus objetivos de aprendizagem".

Portanto, o primeiro passo na leitura é definir qual estilo mais se adequa ao objetivo daquela atividade de leitura. A partir daí, as estratégias se fazem úteis para facilitar o percurso até esse objetivo.

Leitores competentes sabem que, algumas vezes, é necessário ler um texto com muita atenção, e outras vezes basta uma rápida leitura geral para conseguir atingir determinado objetivo. A partir daí, diferenciam-se três tipos básicos de compreensão de leitura: a global, a detalhada e a seletiva. A leitura global serve para extrair as informações principais de um texto; a leitura detalhada procura levar a uma compreensão pormenorizada do conteúdo de textos mais longos; e a leitura seletiva consiste em selecionar blocos específicos de informação contida no texto.

\section{Testando a COMPETÊnCiA de leitura}

Quanto à avaliação da leitura, o PREL (2005, p. 38) afirma que boa parte dos instrumentos de testagem da compreensão são inadequados, pois não representam a complexidade da compreensão e a confundem com outras capacidades do aprendiz - por exemplo, o conhecimento de vocabulário. Além disso, as atividades de avaliação costumam basear-se excessivamente nos conhecimentos prévios do aprendiz (PREL, 2005, p. 38). Segundo Würffel (2013, p. 130), exercícios em que se seleciona entre verdadeiro ou falso ou se resume um texto ocupam-se da promoção da compreensão do texto, e não da compreensão de leitura. Com base em Ehlers (1998), a autora afirma que a compreensão de leitura abrange não somente a compreensão textual, mas também o complexo processo de leitura, que ocorre em três 
níveis, já mencionados neste texto: o nível da palavra, o nível da frase e o nível do texto (WÜRFFEL, 2013, p. 131).

O PREL (2005, p. 38) distingue quatro possíveis relações entre a pergunta a ser respondida em uma avaliação, o texto e os conhecimentos prévios do leitor - isto é, o conhecimento enciclopédico ou de mundo, na descrição de Koch (2007, p. 32). São elas:

- a resposta à questão está escrita diretamente em uma frase do texto;

- a resposta requer pesquisa ao longo do texto;

- a resposta vem de conhecimentos prévios e de pistas dadas pelo texto;

- a resposta vem inteiramente de conhecimentos prévios, e pode ser alcançada sem a leitura do texto (PREL, 2005, p. 20).

O conhecimento sociointeracional não assume um papel de relevância em testes de leitura a serem realizados de maneira individual e silenciosa. Portanto, testes que pretendem aferir a compreensão de leitura devem ser elaborados com base nos conhecimentos gramatical e lexical, com alguma participação dos conhecimentos declarativo e episódico.

\section{A Leitura em LÍNgUA EStRANGeira}

Conforme comentamos na introdução deste artigo, o Quadro Comum Europeu (CONSELHO DA EUROPA, 2001, p. 106) diferencia os seguintes estilos de leitura, de acordo com objetivos possíveis: compreender o essencial, obter informações específicas, compreender pormenores ou compreender as questões implícitas em um texto. Os três primeiros objetivos correspondem claramente às definições de leitura global, seletiva e detalhada, respectivamente, enquanto o último deles é mais facilmente relacionado à leitura argumentativa, expandindo a leitura detalhada até um nível em que as informações presentes no texto formem conexões mais complexas com os conhecimentos prévios de mundo do leitor.

Meireles (2006, p. 309) observa que o leitor de um texto em língua materna frequentemente se depara com situações em que a leitura seletiva é percebida como a melhor escolha, mas o leitor de um texto em LE costuma dar preferência à leitura detalhada. A respeito das estratégias de leitura em LE, o PREL (2005, p. 17-21) sugere como conteúdos explicitamente ensinados em sala de aula: 
- o monitoramento da própria compreensão, buscando soluções para as situações de não entendimento através da releitura ou da reformulação de passagens lidas;

- a criação de um mapa dos acontecimentos de uma narrativa;

- a elaboração de perguntas e respostas sobre informações contidas no texto, entre outros.

Meireles (2006, p. 310) também defende que essas estratégias cognitivas, bem como algumas técnicas de leitura, sejam apresentadas e praticadas durante a aula de LE.

Alguns exemplos de técnicas são: sublinhar com cores diferentes determinados tipos de informação encontrada no texto e reestruturar as frases. As técnicas certamente exercem efeitos positivos também nas práticas de leitura em uma língua que o leitor já domina (BLÜHDORN; ALBERT, 2012, p. 9).

De acordo com Blühdorn e Albert (2012, p. 8), quando o aprendiz começa a ler em LE, tem a sensação de que o maior problema é a falta de conhecimento de vocabulário, e adquire o hábito de sublinhar as palavras desconhecidas. Entretanto, a compreensão do texto fica mais fácil quando se realçam justamente as palavras que foram compreendidas, pois dessa forma o aprendiz constrói "ilhas do compreensível" para usar como ponto de partida.

\section{CONSIDERAÇÕES Finais}

Conforme explicitamos no início deste trabalho, nosso objetivo aqui foi demonstrar por que a compreensão de leitura é mais complexa que a compreensão de um texto, e por que esse fato deve ser considerado, ao testar a leitura em LE.

Uma reflexão sobre o ensino-aprendizagem de leitura em LE passa necessariamente pela compreensão dos sistemas de conhecimento de que o leitor dispõe. $\mathrm{O}$ referencial teórico reunido neste trabalho aponta para o fato de que compreensão de leitura é mais do que compreensão de texto, e que os testes elaborados para aferir a compreensão de leitura costumam mensurar apenas a compreensão de texto. Afinal, a compreensão de leitura bem-sucedida envolve a evolução do processamento consciente para o automático, pois o procedimento de buscar determinadas informações em um texto de forma isolada, a fim de responder a questões pontuais, corresponde ao chamado processamento consciente do texto e envolve o uso de uma única estratégia de leitura, a leitura seletiva. Por isso é possível afirmar que a compreensão de leitura vai além da habilidade de compreender a mensagem de um texto. 
Essas informações são valiosas para o professor de língua, que tem entre suas atribuições elaborar avaliações da compreensão de leitura e propor atividades que estimulem o uso prático das diversas estratégias de leitura e das técnicas para lidar com textos. Sobretudo no âmbito do ensino de LE, é importante garantir que os testes elaborados sejam capazes de exigir do leitor mais do que o processamento consciente das informações contidas no texto e o emprego de técnicas de monitoramento da leitura.

Daí a importância de se manter em mente a diferença entre compreensão de texto e compreensão de leitura: estimular a compreensão de leitura, e não a mera compreensão de um texto, é buscar soluções para que o aprendiz de LE desenvolva duas competências fundamentais para um leitor: a escolha da estratégia de leitura mais adequada dentre as diversas opções disponíveis e o processamento automático das informações lidas.

Pautar os testes de verificação da competência de leitura nesses mesmos critérios, demonstrando coerência entre o conteúdo que se ensina e o aprendizado verificado em avaliações, é o caminho para guiar o aprendiz de língua estrangeira ao objetivo de atingir, na língua-alvo, a mesma fluência de leitura que já conquistou em sua língua materna.

\section{REFERÊNCIAS}

BLÜHDORN, H.; ALBERT, M. F. Leseverstehen für Deutsch als Fremdsprache. Ein Lehrbuch für die Lehrerausbildung. Pisa: Pisa University Press, 2012.

BRASIL. Ministério da Educação. Parâmetros curriculares nacionais: Língua Portuguesa. Brasília: MEC/SEF, 1997.

CONSELHO DA EUROPA. Quadro europeu comum de referência para línguas: Aprendizagem, ensino, avaliação. Porto: Edições ASA, 2001.

ECO, U. Lector in fabula. La cooperazione interpretativa nei testi narrativi. 2. ed. Milão: Bompiani, 1983 [1979].

EHLERS, S. Lesetheorie und fremdsprachliche Lesepraxis aus der Perspective des Deutschen als Fremdsprache. Tübingen: Gunter Narr Verlag, 1998.

EHLERS, S. Übungen zum Leseverstehen. In: BAUSCH, K. R.etal.Handbuch Fremdsprachenunterricht. 5. ed. Tübingen/Basel: A. Francke, 2007. p. 287-292.

JOUVE, V. A leitura. Tradução de Brigitte Hervor. São Paulo: Unesp, 2002.

KOCH, I. V. O texto e a construção dos sentidos. São Paulo: Contexto, 2007.

KOCH, I. V.; ELIAS, V. M. Ler e compreender: os sentidos do texto. 2. ed. São Paulo: Contexto, 2006.

LEFFA, V. J. Perspectivas no estudo da leitura: texto, leitor e interação social. In: LEFFA, V. J.; PEREIRA, A. E. (Org.). O ensino da leitura e produção textual: alternativas de renovação. Pelotas: Educat, 1999. p. 13-37. Disponível em: http://www.leffa.pro.br/textos/trabalhos/perspec.pdf. Acesso em: 13 jul. 2017. 
LUTJEHARMS, M. Vermittlung der Lesefertigkeit. In: KRUMM, H. J. et al. Deutsch als Fremd- und Zweitsprache. Ein internationales Handbuch. Berlin/New York: de Gruyter, 2010. v. 1, p. 976-982. MEIRELES, S. Leseverstehen aus der Perspektive des Nicht-Muttersprachlers. In: BLÜHDORN, H. et al. (Org.). Textverstehen: Grammatik und darüber hinaus. Berlin/New York: de Gruyter, 2006. p. 299-314.

PREL - Pacific Resources for Education and Learning. A focus on comprehension, 2005. Disponível em: http://www.prel.org/programs/rel/rel.asp. Acesso em: 7 jul. 2017.

VAN DIJK, T. A.; KINTSCH, W. Strategies of discourse comprehension. New York: Academic Press, 1983. WÜRFFEL, N. Strategiengebrauch bei Aufgabenbearbeitungen in internetgestütztem Selbstlernmaterial. Tübingen: Gunter Narr, 2006.

WÜRFFEL, N. Leseverstehen. In: OOMEN-WELKE, I.; AHRENHOLZ, B. (Org.). Deutsch als Fremdsprache. Baltmannsweiler: Schneider Hohengehren, 2013. p. 130-141.

\section{SObRe A AUtora}

Marina Grilli. Mestra em Letras e Doutoranda em Educação pela USP. E-mail: marina.grilli.s@gmail.com.

Recebido em 12 de dezembro de 2019 e aprovado em o7 de abril de 2021. 